NBER WORKING PAPER SERIES

\title{
WHY DO INCUMBENT SENATORS WIN? EVIDENCE FROM A DYNAMIC SELECTION MODEL
}

\author{
Gautam Gowrisankaran \\ Matthew F. Mitchell \\ Andrea Moro \\ Working Paper 10748 \\ http://www.nber.org/papers/w10748
NATIONAL BUREAU OF ECONOMIC RESEARCH
1050 Massachusetts Avenue
Cambridge, MA 02138
September 2004

We thank Ethan Bueno de Mesquita, Zvi Eckstein, Barton Hamilton, Antonio Merlo, Larry Samuelson, Kenneth Wolpin, seminar participants at numerous institutions and 2002-03 Industrial Organization graduate students at Harvard and Yale for their insightful comments and Anita Todd for editorial assistance. Gowrisankaran acknowledges financial support from the National Science Foundation (Grant SES-0318170). Any opinions, findings, and conclusions or recommendations expressed herein are those of the authors and do not necessarily reflect the views of the National Science Foundation, the Federal Reserve Bank of Minneapolis, or the Federal Reserve System. The views expressed herein are those of the author(s) and not necessarily those of the National Bureau of Economic Research.

(C2004 by Gautam Gowrisankaran, Matthew F. Mitchell, and Andrea Moro. All rights reserved. Short sections of text, not to exceed two paragraphs, may be quoted without explicit permission provided that full credit, including $(\odot$ notice, is given to the source. 
Why Do Incumbent Senators Win? Evidence from a Dynamic Selection Model Gautam Gowrisankaran, Matthew F. Mitchell, and Andrea Moro

NBER Working Paper No. 10748

September 2004

JEL No. H1, J2, C5

\begin{abstract}
$\underline{\text { ABSTRACT }}$
Since 1914, incumbent U.S. senators running for reelection have won almost $80 \%$ of the time. We investigate why incumbents win so often. We allow for three potential explanations for the incumbency advantage: selection, tenure, and challenger quality, which are separately identified using histories of election outcomes following an open seat election. We specify a dynamic model of voter behavior that allows for these three effects, and structurally estimate the parameters of the model using U.S. Senate data. We find that tenure effects are negative or small. We also find that incumbents face weaker challengers than candidates running for open seats. If incumbents faced challengers as strong as candidates for open seats, the incumbency advantage would be cut in half.
\end{abstract}

\title{
Gautam Gowrisankaran
}

John M. Olin School of Business

Washington University in St. Louis

Campus Box 1133

One Brookings Drive

St. Louis, MO 63130

and NBER

gowrisankaran@wustl.edu

Matthew F. Mitchell

Department of Economics

University of Iowa

matthew-mitchell@uiowa.edu

Andrea Moro

Department of Economics

University of Minnesota

amoro@econ.umn.edu 


\section{Introduction}

In a variety of electoral situations, incumbents win substantially more than half of the time. This is sometimes referred to as an incumbency advantage. This paper investigates the sources of the incumbency advantage in the U.S. Senate, where incumbents win almost $80 \%$ of the time.

While many explanations have been posited to explain the incumbency advantage, including pork-barrel spending, media coverage, and incumbent visibility, one important explanation is that some of the incumbency advantage is due to a selection effect: becoming an incumbent requires winning, and winning candidates will tend to be of relatively high quality. In this case the incumbency advantage is not due to any direct benefit of incumbency but is rather a consequence of the different distribution of quality for incumbents. The goal of this paper is to empirically disentangle the selection effect from other sources of incumbency advantage, principally the effect of tenure and the fact that the quality of challengers facing incumbents running for reelection may be low relative to the quality of candidates in open seat elections (that is, elections without incumbents).

We formulate a simple model of voter decisions for candidates incorporating selection and other effects that can explain the incumbency advantage. The model implies that the tenure of the incumbent and the history of the seat following an open seat election (e.g., how many terms were served by each candidate who was later defeated by another candidate) will influence the probability of reelection in different ways depending on the relative importance of selection and other effects. We first examine what simple counts from U.S. Senate data of winning probabilities by incumbent's tenure and terms since an open seat election imply about the sources of the incumbency advantage. To more precisely understand the implications of the data, we structurally estimate the parameters of the model, and use the estimated model to examine the relative importance of the different sources of incumbency advantage.

The model of voters and candidates we present in Section 3, though stylized, seeks to capture some of the basic forces of incumbency advantage. In our model, 
voters obtain utility from their elected official through two sources. First, each candidate has a permanent, idiosyncratic quality, which voters value. Second, voters value the tenure of their elected official. There are several possible sources of tenure effects. Elected officials may learn on the job, they may use tenure to achieve better status within the Senate, or they may use the exposure of incumbency to their advantage in elections. It also could be that candidates become out-of-step with their constituents or that their skills deteriorate over time. We do not attempt to separate these different sources of the tenure effects, as it is beyond the scope of our model and data. Instead, we simply seek to evaluate the importance and variation of tenure effects, and to separate them from the selection effect. Importantly, we do not restrict the tenure effects to be increasing in tenure or follow any other pattern.

We model voters in each senatorial seat as identical dynamically optimizing agents. Voters observe the permanent quality of two current candidates and then elect one of them. Permanent candidate quality is drawn from a fixed distribution, which varies depending on whether the election is an open seat election or one where an incumbent is running. Once quality is drawn, the only change in the utility flow from a candidate over his career is his tenure effect, which moves in an identical way across elected officials. An incumbent leaves the Senate with an exogenous exit probability that depends on tenure. As such, we do not account for the selection bias that may result from senators choosing when to retire based on their electoral prospects. $^{1}$

We base our estimation on U.S. Senate data since 1914, which marks the start of the elected senate. Our data contain the history of senatorial seats, recording how candidates came to office, how long they served in office and the reason they left office. Conditional on a given vector of structural parameters, the solution to the

\footnotetext{
1 Although we are not aware of any evidence on the exogeneity of retirement from the Senate, Kiewiet and Zeng (1993) find that age is the most important determinant of the retirement decision for House representatives, with scandals a distant second. Indicators of quality such as chairmanship of a committee, party leadership, or the victory margin in the previous election are not statistically significant. These findings support our choice of exogenous exit probabilities to the extent that they apply to the behavior of senators. Ansolabehere and Snyder Jr. (2004), using term limits as an instrumental variable, also find no evidence that candidates are strategic in their retirement decisions.
} 
voter's dynamic choice problem implies a probability distribution over the possible electoral histories of a senatorial seat. We derive this distribution and use it to estimate the parameters of the model with the method of maximum likelihood.

The model allows us to identify selection and tenure effects separately in a relatively intuitive way. The key feature of the data that allows identification is that two senators with identical tenure could have important differences in their electoral history and the winning probability of an incumbent depends on the entire history of the seat. For instance, a one-term incumbent could have beaten a two-term incumbent, or he could have beaten a five-term incumbent. If five-term incumbents almost never lose, then the econometrician's posterior distribution of permanent quality for the one-term incumbent who beats a five-term incumbent will be different from the posterior distribution for a one-term incumbent who beats a two-term incumbent. If selection based on candidate quality is an important determinant of the incumbency advantage, then these two incumbents would have quite different probabilities of reelection despite their identical tenure. Thus, the importance of selection will be identified based on how the electoral history affects reelection probabilities, conditioning on incumbent tenure.

We can understand some of the impact that these basic forces of identification will have on our predicted sources of incumbency advantage by examining the winning probabilities in the data by tenure and terms since an open seat election. ${ }^{2}$ The data reveal that incumbent senators who initially won an open seat election have roughly an $80 \%$ probability of winning reelection in every election after the first election. As selection implies increasing reelection probabilities if tenure effects are constant or increasing in tenure, the constant probabilities suggest that tenure effects cannot be increasing in tenure. Comparisons of reelection probabilities of candidates with identical tenure who differ by whether or not they won open seat elections suggest that the quality of candidates is higher in open seat elections than in other elections.

In order to precisely quantify the sources of the incumbency advantage, we turn

\footnotetext{
2 These counts are shown in Table 1 in Section 5.1.
} 
to our structural model. Our structural estimation results show that tenure effects are negative or small and that two other factors explain the incumbency advantage. First, incumbents are of higher average quality due to selection effects. Second, on average, incumbents face a weaker pool of challengers than do candidates running for an open seat. In our data, incumbents win $78 \%$ of the time. Without differences in the distributions of candidate quality across elections, incumbents would only win about $63 \%$ of the time, while with no differences in quality whatsoever, any candidate would have a 50\% chance of winning any election. This suggests that candidate heterogeneity accounts for about half of the incumbency advantage.

Our base specification is very parsimonious in that it does not use characteristics of candidates, elections, states, or time. We realize that there are important differences across these variables that might influence the incumbency advantage. We make this choice because even this simple model yields intuitive testable predictions as to the sources of incumbency bias, and because predicted moments from the structural estimation, based on reelection probabilities by candidate tenure and history, fit the data reasonably well.

However, as a robustness check, in Section 5.3 we specify models with unobserved heterogeneity where the parameters vary across time and regions. ${ }^{3}$ This specification would allow for the possibility that some states have huge, positive tenure effects (e.g., "safe" states where, for instance, a candidate of the prevailing political party has an inherent advantage), while others have moderately negative tenure effects. While the point estimates we computed do suggest the possibility of such a dichotomy, a likelihood ratio test reveals that this specification does not significantly improve the model's ability to explain the data relative to the specification without unobserved heterogeneity.

\footnotetext{
3 Our specification follows Heckman and Singer (1984).
} 


\section{Relationship to the existing literature}

Starting in the 1970s, a vast literature has developed that has tried to quantify incumbency advantages. ${ }^{4}$ Early studies regressed the winning probability on an incumbency dummy. As we discussed above, interpreting a positive coefficient in this regression as a tenure effect is problematic because the positive coefficient may be due to a selection effect. The first method to try to separate the tenure and selection effects defined the tenure effect as the difference between the vote share that a senator earned in his second and first elections. This measure became known as the sophomore surge. ${ }^{5}$ Gelman and King (1990) pointed out that the sophomore surge approach also suffers from selection bias because a candidate who is elected would disproportionately have had a good draw in his first election, that may be idiosyncratic to the first election. They developed a reduced-form least squares method that helps mitigate this selection bias. Levitt and Wolfram (1997) apply a Heckman-style correction to the sophomore surge to further mitigate the Gelman and King (1990) selection bias. Separately, Levitt and Wolfram (1997) attempt to separate the sources of incumbency advantage into increased incumbent quality and decreased challenger quality, by considering pairs of elections where the same two candidates face each other.

Our paper builds on these earlier papers, in that we recognize, and attempt to control for, the problem of selection bias that is inherent in an electoral system. Our model incorporates the fact that an incumbent who won had a positive idiosyncratic shock in the first period, as in Gelman and King (1990). The idiosyncratic shock occurs because the winner of an open seat election likely faced a competitor whose quality was less than the average candidate quality in an open seat election, but will face a challenger of average quality in his second election. As in Levitt and Wolfram (1997), we consider specifications where the new candidate density can differ based

4 Most studies use House election data, which contain a larger number of elections. They typically regress winning probabilities on a set of regressors. See the references in the surveys by Cover and Mayhew (1977), Fiorina (1989), and Mayhew (1974). For more recent studies, see also Ansolabehere and Snyder Jr. (2002), Ansolabehere and Snyder Jr. (2004), Cox and Katz (1996), and Lee (2001), together with the other references cited in this section.

5 See Erikson (1971), Cover (1977), Gelman and King (1990) and references therein. 
on whether the candidate is in an open seat election or not.

Our approach differs from the approach of these papers in several important ways. First, we estimate parameters that are fully consistent with an optimizing model of voter behavior. Thus, there are no longer any questions as to whether our estimates suffer from selection bias, conditional on our model being accurate. Second, our model is identified by the entire history of electoral outcomes since the open seat election, and not just by the data from the current election. ${ }^{6}$ This allows us to identify our parameters of interest without using the limited (and potentially biased) information available from when pairs of candidates face each other multiple times. Third, our model generalizes the sophomore surge approach, in that it allows for tenure effects, which we can estimate separately from the effect of selection, by using the entire history of outcomes. Fourth, we use data from the U.S. Senate, and not the U.S. House of Representatives. This allows us to avoid having to deal with the problems inherent in redistricting. ${ }^{7}$ Fifth, we do not include many of the covariates used in earlier studies. We made this choice because we need to keep the number of state variables to a minimum in order to estimate the dynamic model. Finally, we use data only on election wins and not on vote shares. We made this decision in order to estimate parameters that are consistent with a well-specified model and because vote shares are more likely to be biased by endogenous challenger quality and effort, which we do not model.

Because of these differences in our approach, our results differ substantially from these other studies. We believe that an advantage to our approach is that the factors in the data that generate our results are readily apparent and broadly present in the Senate data, as we discuss in Section 5.1.

A related literature has structurally estimated candidate career decisions to retire or face reelection. Both strands of the literature attempt to predict reelection probabilities. Diermeier et al. (2002) estimate a model where candidate career decisions

6 In this way, our model relates to Samuelson (1987), who first recognized the importance of the entire history of a seat in evaluating incumbency advantage.

7 Redistricting is problematic because it is difficult to define incumbency and electoral outcomes in the case where one district is formed from parts of more than one district. 
are endogenous but reelection probabilities are exogenous. In contrast, we endogenize reelection probabilities but treat retirement decisions as exogenous. We view our approach as complementary to a career decision model, as we seek to examine the extent to which endogenous voter decisions can explain reelection probabilities, but we do not model endogenous retirement decisions.

\section{The Model}

We model voters in each senatorial seat as identical dynamically optimizing agents who value services from an elected official, in our case a senator. The valuation has two components: a senator-specific, permanent quality $q$ and a tenure effect $\tau_{m}$ common to all senators of tenure $m .^{8}$ The quality $q$ is an element of a compact set $Q$. Tenure is defined by the number of completed terms in office. Both $q$ and $m$ are observed by the voters. The utility flow for the voter in a given period is additive in these two components, i.e.,

$$
u(q, m)=q+\tau_{m}
$$

The voter values the expected sum of current and future utility flows, discounted by $\beta<1$.

In each period, voters choose between two candidates in an election. There are two kinds of elections between which it is useful to distinguish. One is an incumbentchallenger election. This is an election where an incumbent runs against a challenger. The other type is called an open seat election, which takes place in situations where neither candidate is an incumbent. This happens when incumbents leave office for reasons other than losing an election. We assume that these reasons are exogenous and depend only on tenure.

The timing is as follows. At the beginning of the period, the incumbent either exits or runs for reelection. Denote the probability of exit at tenure $m$ by $\delta_{m}$. If he

\footnotetext{
8 Our notation includes $\tau_{0}$, which is to be interpreted as the tenure effect of candidates with zero tenure. We argue below that this parameter is not empirically separately identified from the mean of the candidate's quality distribution. We include it here to simplify the formal description of the dynamic program.
} 
exits, two new candidates run for the seat. If he runs for reelection, a single challenger runs against the incumbent. Each new candidate then draws his permanent quality $q$ from an atomless distribution $F(q)$ with corresponding density $f(q) .{ }^{9}$ In the estimation, we allow $F$ to differ depending on the type of election, to account for possible differences in the quality distribution of candidates running in open seat elections vs. challengers running against incumbents. For simplicity of notation we abstract from this in the description of the model.

The tenure effects $\tau_{m}$ are tenure-specific constants known to the voter. The voter observes the qualities of the current candidates and then elects the candidate that maximizes expected discounted utility. The voter also knows the distribution $F$ from which future candidates will draw their permanent qualities.

For an open seat election, the optimal choice of the voter is simple: choose the candidate with the higher $q$. The utility flows generated by the candidates are otherwise identical.

In an incumbent-challenger election the decision is more complicated. We express the problem recursively using a Bellman equation. Denote by $q$ the quality of the incumbent and by $q_{c}$ the quality of the challenger. The voter's decision can be expressed as a function of the incumbent senator's quality $q$ and tenure $m$. Let $V(q, m)$ denote the expected discounted utility for the voter at the beginning of the period, before either exit occurs or new candidates appear. Let $W$ denote the expected discounted utility from an open seat. Then,

$$
V(q, m)=\left(1-\delta_{m}\right) \int_{Q} \max \left\{\begin{array}{l}
q+\tau_{m}+\beta V(q, m+1), \\
q_{c}+\tau_{0}+\beta V\left(q_{c}, 1\right)
\end{array}\right\} f\left(q_{c}\right) d q_{c}+\delta_{m} W .
$$

If the incumbent chooses to run again (which occurs with probability $1-\delta_{m}$ ), the voter chooses between the incumbent and a challenger. The integral in the first term in (2) reflects the expected utility in this case, which involves integrating over $q_{c}$.

If the incumbent exits, creating an open seat election, the voter obtains $W$.

9 We assume that $F$ is atomless to ensure that the voter has strict preferences over candidates with probability one. 
Letting the two new candidates' qualities be defined by $q$ and $q_{c}$,

$$
W=\int_{Q} \int_{Q} \max \left\{\begin{array}{l}
q+\tau_{0}+\beta V(q, 1), \\
q_{c}+\tau_{0}+\beta V\left(q_{c}, 1\right)
\end{array}\right\} f(q) d q f\left(q_{c}\right) d q_{c} .
$$

The value of the open seat reflects the fact that two candidates are drawn and the higher $q$ is retained.

Denote by $r\left(q, q_{c}, m\right)$ the optimal reelection rule of a voter when the incumbent has quality $q$ and tenure $m$ and the challenger has quality $q_{c} ; r\left(q, q_{c}, m\right)=1$ denotes reelecting the incumbent and $r\left(q, q_{c}, m\right)=0$ denotes choosing the challenger. We now show that the solution to the decision problem can be characterized as a cutoff rule. As a result, the Bellman equation takes a simple form that is useful in computing the solution. We start by characterizing the decision rule.

Lemma $1 r\left(q, q_{c}, m\right)$ is weakly decreasing in $q_{c}$.

The proof is in Appendix A.1. The lemma implies that the voter follows a cutoff rule: challengers are elected only if their quality exceeds a cutoff $\bar{q}(q, m)$. Note that voters do not simply choose the candidate with the higher $q$, or even the higher $q+\tau_{m}$, since the voter is forward-looking and considers future tenure effects and exit probabilities.

The cutoff rule allows us to express the Bellman equation more concisely. We do this by defining $V(q, 0)$ to be the voter's value function from an open seat election where one candidate has drawn $q$ and a second candidate's quality has yet to be drawn. Then, by letting $\delta_{0}=0$, equation (2) can be rewritten as

$$
\begin{aligned}
V(q, m)= & \left(1-\delta_{m}\right) \max _{\bar{q}}\left(\begin{array}{l}
F(\bar{q})\left(q+\tau_{m}+\beta V(q, m+1)\right) \\
+\int_{\bar{q}}^{\infty}\left(x+\tau_{0}+\beta V(x, 1)\right) d f(x) d x
\end{array}\right) \\
& +\delta_{m} \int_{Q} V(x, 0) d f(x) d x .
\end{aligned}
$$

If the incumbent does not exit (the case given in (4a)), the expected return has two components: first, the payoff when the incumbent is retained, times the probability of retention $F(\bar{q})$; second, the expected value of the challenger, conditional on his 
quality being above $\bar{q}$. When the incumbent exits, the flow utility enjoyed by the voter $\delta_{m} W$ in (2) can be rewritten as (4b) by using (4) and $\delta_{0}=0$ to define $V(x, 0)$.

\section{Estimation}

\subsection{Overview}

Our goal is to provide inference on the fundamental parameters of our model: the candidate permanent quality density $f$, the tenure effects $\tau_{m}$, the exit probabilities $\delta_{m}$, and the discount factor $\beta$. Our data contain information on when and how each U.S. senator came to office and when and how he left office. These data allow us to understand, for instance, whether a senator came to office by winning an open election or by defeating an incumbent.

We do not directly observe any component of quality. However, given a vector of fundamental parameters, the model generates a probability distribution over sequences of electoral outcomes. We use the method of maximum likelihood to find the parameter values that maximize the probability of seeing the observed electoral outcomes.

To understand how the model provides evidence on reelection probabilities that we observe in the data, it is useful to consider a special case. Suppose that tenure effects and exit probabilities are constant across tenure, i.e. $\tau_{m}=\bar{\tau}$ and $\delta_{m}=\bar{\delta}$. In this case, the policy function satisfies $\bar{q}(q, m)=q$; the voter always chooses the candidate with the higher $q$ because tenure does not affect current or future payoffs.

Suppose that candidate $A$ won an open seat election in 1960 against candidate $B$ and then defeated challenger $C$ in 1966. After that election, we know that $A$ 's permanent quality $q$ is distributed as the maximum of 3 i.i.d. draws from $F$. Suppose instead that $C$ had won in 1966 . Then, we can infer instead that $C$ 's permanent quality is distributed as the maximum of 3 i.i.d. draws from $F$. Thus, the probability of the incumbent winning in 1972 depends solely on the number of elections that have occurred since the last open election for that seat. As a result, the probability of reelection will be increasing in the number of terms since an open seat, and 
conditionally independent of tenure.

In general, the probability of reelection will depend on the entire history of wins and losses since an open seat election. Let us extend the electoral history of the previous paragraph to consider the 1972 election, and suppose that the challenger, $D$, wins in 1972. In the case where $\tau_{1}=\tau_{2}=\bar{\tau}$, our posterior on the permanent quality of $D$ is independent of whether he beat $A$ or $C$. However, consider the case where tenure effects depend on tenure, for example $\tau_{1}<\tau_{2}$. For simplicity, assume that $\beta=0$. If $D$ defeated the two-term incumbent $A$ in 1972 , then $D$ must have had a sufficiently high $q$ to overcome his deficit in tenure effects $\tau_{2}-\tau_{1}$. In contrast, we cannot make the same inference if $D$ defeated the one-term incumbent $C$ in 1972. Thus, our posterior density of the permanent quality of $D$ is higher if he beat $A$ than if he beat $C$.

Extending this example to $1978, D$ 's probability of being reelected depends not only on his tenure (1 term) and the number of terms since an open seat election (3 terms), but also on whether he beat $A$ or $C$. This example demonstrates why the entire history matters.

The example also suggests how our model can separately identify tenure effects from selection effects. Conditional on a candidate's tenure, the model will, for different parameter values, predict different probabilities of reelection given different histories since the last open seat election. By matching these predictions of the model to the data, we can understand the relative importance of selection and tenure effects.

This discussion also illustrates the difficulty of using regressions to separate tenure effects from selection effects, as previous studies have attempted to do. To be consistent with the model, one cannot simply regress the probability of reelection on candidate tenure and simple statistics such as terms since an open seat or number of senators since an open seat. The regressors would instead have to include the entire history since the open seat election, which would imply thousands of regressors for our data set.

We now turn to the specifics of our data and our inference procedure. 


\subsection{Data and Institutional Background}

We construct our data set using data on U.S. Senate elections from the Roster of U.S. Congressional Office Holders (ICPSR 7803). In the original data set each record refers to a senator seated in a given congress (a two-year period starting in odd-numbered years) and contains information about when and why the senator was seated and when and why he left congress. The ICPSR data set ends in 1998. We compiled more recent data in order to extend this data set up to the 2002 election. $^{10}$

We use these data to construct records of histories from an open seat election to an exit. We refer to one such history as a chain. Each chain is a vector of zeros and ones, with dimension equal to the number of elections held between the open seat election and the exit of the last senator in the chain. We do not include the outcomes of open seat elections in the chain. The first element of the vector is equal to one if the winner of the open seat election wins his next election; that element is equal to zero if the challenger wins. The second element is equal to one if the winner of the second election wins the third election, and it is equal to zero if his challenger wins, etc.

The normal term of a senator is six years. Regular elections are held in November of even-numbered years, and senators take office in the January following their election. Each Senate seat belongs to one of three classes, based on the the year in which its regular elections are held.

Senators can leave office at the end of their terms essentially for three reasons, losing a general election, losing a primary election or retiring. Our data contain instances where senators leave office before the end of a six-year term because of death, retirement, or moving to a different office or job. In this case, an election is held on or before the next even-numbered November. The election is called a special election unless that senatorial seat was scheduled to have an election at that time. The governor of the state often appoints an individual to serve as senator until someone is elected.

\footnotetext{
10 To gather the most recent data, we collected and compared information from various sources, including the Biographical Directory of the United States Congress (see http://bioguide.congress.gov).
} 
Every chain starts with an open seat. Open seat elections consist of all elections following the exit of a candidate because of death or retirement. ${ }^{11}$ As a consequence, we treat all special elections as open seat elections even if one of the candidates briefly served as an unelected senator nominated by the governor. Our definition of an open seat election also implies that an election where the incumbent senator lost in the primary is not an open seat election. We treat the primary and general elections as a single election with two candidates.

We treat all elections, whether special or regular, as counting for one term. This simplification is imperfect because the time period in our model is one term, and so the voter is assumed to discount the future identically if there are four years between elections (due to a special election) or if there are six years between elections. Moreover, the interpretation of the tenure effects is that they depend on number of elections won rather than number of years served.

Senators have been elected by popular vote only since 1914, as initiated by U.S. Constitutional Amendment XVII. Before this change, senators were appointed by the state legislature. As we do not have a model of how the state legislature chose senators, we only consider data from elections held on or after 1914. Moreover, it is conceptually difficult to use chains that started before 1914 because we do not have a model for the density of permanent quality for an incumbent senator after 1914 unless every senator in his chain was elected and not appointed. Thus, our data set contains only chains that start on or after 1914.

The use of these Senate data avoids several pitfalls present in other data sources. In particular, the U.S. House of Representatives contains many instances of redistricting and it is not clear how to treat elections following a redistricting, when two incumbents may run against each other.

Our data set contains 389 chains, with 593 different senators and 1330 elections. We observe an exit preceding each of these 389 chains. Out of the 389 exits, 72 required a special election to choose the next senator. Considering all elections besides open seat elections, the incumbent senator won 737 out of 941 times (78\%).

11 We observe cases where a senator loses an election and then retires between the election and the end of his term. We ignore the retirement decision in these cases. 
Of the 204 incumbent losses, 43 occurred during the primary, with the rest occurring during the general election.

Among the chains, 81 have dimension zero, which occurs when the winner of the open seat election exits without running for reelection. The chains contain at most 7 different senators and at most 15 elections. The longest tenure for a senator was Senator Strom Thurmond, who served from 1954 to 2002, winning 8 elections. Only 23 senators served more than 5 terms. To avoid estimating parameters with very few observations, we assume that $\tau_{m}=\tau_{5}$ and $\delta_{m}=\delta_{5}$ for all $m \geq 5$.

\subsection{Inference and Likelihood}

As is well-known in the literature, it is difficult to estimate the discount factor of a dynamic discrete choice problem (see Rust (1987) and Magnac and Thesmar (2002)). We consider $4 \%$ to be a reasonable discount rate on an annual basis. Given that a regular term lasts six years, we set $\beta$ equal to 0.96 to the power of six. In principle, we could jointly estimate all of the other parameters. However, since we treat the retirement probability as exogenous, we can obtain consistent estimates of the retirement probabilities $\delta_{m}$ without solving the voter's decision problem. Specifically, we estimate $\delta_{m}$ as the number of senators who retire with tenure $m$ divided by the total number of senators that held office for at least $m$ terms.

We allow the quality distribution of new candidates to vary depending on the type of elections. Specifically, we assume that candidates in an open seat election draw permanent quality $q$ from a distribution $F_{o}$, whereas challengers of incumbents draw their permanent quality from a distribution $F_{c}$. We assume that both distributions are normal with means $\mu_{o}$ and $\mu_{c}$ and variances $\sigma_{o}$ and $\sigma_{c}$, respectively. ${ }^{12}$ Note that $\mu_{o}$ and $\mu_{c}$ are not separately identified given our data: a shift in both means would not change any observable prediction of the model. Thus, we normal-

\footnotetext{
12 Note that the support of the normal density is not compact, which is inconsistent with the assumption, made in Section 3, that the densities are drawn from a compact set $Q$. We made this assumption solely to facilitate the proof of Lemma 1. This proof can be extended to the normal density by considering truncations of the density to an interval $[-a, a]$, and letting $a$ go to infinity. An example of this approach is contained in Mitchell (2000).
} 
ize $\mu_{c}=0$ and estimate $\mu_{o}$. Similarly, we cannot separately identify $\sigma_{o}$ from $\sigma_{c}$, because multiplying both standard deviations by the same factor has the same effect of changing the unit of measurement of the candidates' quality. Thus, we normalize $\sigma_{c}=1$. Although $\sigma_{o}$ is then identified from the data, we also normalize $\sigma_{o}=1 \mathrm{in}$ the interest of parsimony. ${ }^{13}$ Finally, adding a constant to $\tau_{0}$ and the same constant to $\tau_{1}, \ldots \tau_{5}$ would yield the same predictions. Therefore, we set $\tau_{0}=0$.

We now discuss the estimation of the parameters. Consider first the contribution to the likelihood of chain $d$ of dimension $T$. Denote the history of wins and losses prior to the $t^{t h}$ election in the chain with the vector $h_{t} \equiv\left\langle d_{1}, \ldots d_{t-1}\right\rangle .{ }^{14}$ Denote the posterior density over incumbent quality after history $h_{t}$ as $g\left(\cdot \mid h_{t}\right)$, and the number of terms served by the incumbent holding office after history $h_{t}$ as $m_{h_{t}}$. Define $e_{t}$ as the random variable that indicates the outcome of the $t^{t h}$ election in the chain, with the interpretation that $e_{t}=1$ indicates the incumbent winning the election and $e_{t}=0$ indicates the incumbent losing. We can then express the likelihood $L$ of chain $d$ as:

$$
\begin{aligned}
L\left(d \mid \tau_{1}, \ldots, \tau_{5}\right) & =\prod_{t=1}^{T} \operatorname{Pr}\left(e_{t}=d_{t} \mid h_{t}\right) \\
& =\prod_{t=1}^{T} \int\left\{\begin{array}{l}
d_{t} \cdot F_{c}\left(\bar{q}\left(x, m_{h_{t}}\right)\right) \\
+\left(1-d_{t}\right) \cdot\left[1-F_{c}\left(\bar{q}\left(x, m_{h_{t}}\right)\right)\right]
\end{array}\right\} d g\left(x \mid h_{t}\right) d x .
\end{aligned}
$$

The expression (5) depends on the policy function $\bar{q}$, which in turn depends on the parameters. The expression also depends on the density of permanent quality for the incumbent at the start of period $t, g\left(x \mid h_{t}\right)$. We evaluate this density using Bayes' Law and the policy function $\bar{q}$. Let the prior density of the incumbent at time $t$ (by the econometrician) be denoted $p$ and decompose history $h_{t}$ into two elements: the outcome of last period election $d_{t-1}$ and the previous history $h_{t-1}$.

\footnotetext{
13 We estimate a specification where we constrain $f_{o}=f_{c}$. For this specification, we set $\mu=0$ and $\sigma=1$, as these parameters are not identified.

14 Recall from our definition of a chain that the first element, $d_{1}$, is the outcome of the incumbentchallenger election following the initial open seat election. Hence this vector does not contain the outcome of the open seat election, which has no informational content for our purposes.
} 
Bayes' Law implies

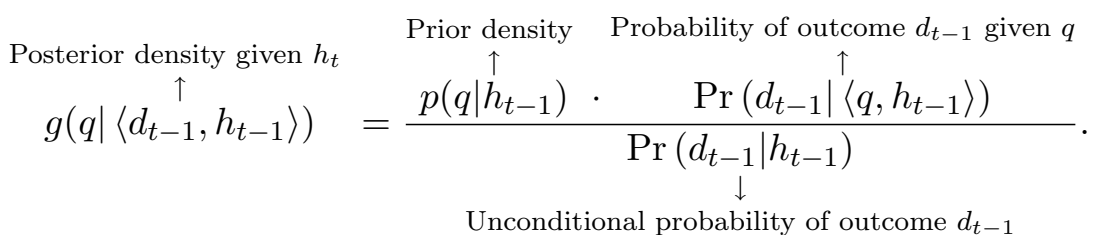

The prior density $p$ is equal to $f_{o}$ if the incumbent won an open seat election in the previous period, and $f_{c}$ if the incumbent won against a previous incumbent. In all other cases, $p$ is defined recursively as equal to $g\left(\cdot \mid h_{t-1}\right)$.

We now show how this formula is applied to the different cases. First, consider the density of a one-term incumbent who won an open seat election in the previous period. In this case the prior density is $f_{o}$, and the conditional probability of winning the open seat given $q$ is $F_{o}(\bar{q}(q, 0))$. For this case, (6) can be written as:

$$
g\left(q \mid h_{0}\right)=\frac{f_{o}(q) \cdot F_{o}(\bar{q}(q, 0))}{\int_{Q} f_{o}(x) \cdot F_{o}(\bar{q}(x, 0)) d x} .
$$

Next, consider the cases with $t>1$. We distinguish two cases, depending on whether the incumbent won or lost in the previous election. If $d_{t-1}=1$, then the conditional probability of the election outcome in the previous period is equal to the probability that the challenger draws a permanent quality less than the threshold value $\bar{q}\left(q, m_{h_{t-1}}\right)$, hence:

$$
g\left(q \mid h_{t}\right)=\frac{g\left(q \mid h_{t-1}\right) \cdot F_{c}\left(\bar{q}\left(q, m_{h_{t-1}}\right)\right)}{\int_{Q} g\left(\left.x\right|_{h_{t-1}}\right) \cdot F_{c}\left(\bar{q}\left(x, m_{h_{t}-1}\right)\right) d x} .
$$

Finally, if $d_{t-1}=0$, the incumbent was a challenger at $t-1$. This means that the prior density is $f$ and that his permanent quality $q$ is greater than the threshold $\bar{q}(\cdot)$ implied by the voters' decision rule, which is a function of the previous incumbent's quality and history. Since the previous incumbent quality is distributed according to $g\left(\cdot \mid h_{t-1}\right)$, then equation (6) can be written as:

$$
g\left(q \mid h_{t}\right)=\frac{f_{c}(q) \cdot \int_{z: \bar{q}\left(z, m_{h_{t-1}}\right)<x} g\left(z \mid h_{t-1}\right) d z}{\int_{Q} f_{c}(q) \cdot \int_{z: \bar{q}\left(z, m_{h_{t-1}}\right)<x} g\left(z \mid h_{t-1}\right) d z d x} .
$$


In order to evaluate the log likelihood of our data set for a given parameter vector, we first compute the policy function using numerical dynamic programming. We then evaluate the likelihood for a chain using the computed policy function, together with (5) and (6), and sum the log of the likelihood for each chain. Details on the numerical procedure used in the estimation are in Appendix A.2.

\section{$5 \quad$ Results}

We first examine simple data on reelection probabilities, in order to understand what the data imply about the possible values of the parameters. We then turn to the structural estimation results. Last, we perform a variety of robustness checks, to ensure the accuracy of our base structural estimation results.

\subsection{Evidence from Data}

Our model implies that the history of a seat since an open seat election will affect the probability of reelection. We encapsulate the history of a seat at any election with two simple statistics: the number of terms since an open seat election and the number of terms that the incumbent had previously served. Table 1 provides a grid that breaks down the probability of an incumbent winning based on these two factors. ${ }^{15}$

We first consider the diagonal of this table to understand what it implies about tenure effects. The diagonal provides the reelection probabilities for candidates who are initially elected to the Senate by winning an open seat election. The first element shows that winners of open seat elections who do not exit during their first term in office win $79 \%$ of the time in their next election. The second element shows that open seat winners who survive reelection and who do not exit during their first two terms in office have a conditional reelection probability of $78 \%$. The conditional reelection probabilities with three or more terms are very similar to these two numbers.

\footnotetext{
15 We exclude open seat elections from this table, as they provide no information in the context of our model.
} 
Terms since last open seat election

\begin{tabular}{|c|c|c|c|c|c|}
\hline & 1 & 2 & 3 & 4 & $\geq 5$ \\
\hline \multirow{2}{*}{1} & $.79(.02)$ & $.72(.06)$ & $.63(.08)$ & $.57(.09)$ & $.77(.06)$ \\
\hline & $N=308$ & $N=50$ & $N=41$ & $N=28$ & $N=47$ \\
\hline \multirow{2}{*}{2} & & $.78(.03)$ & $.76(.09)$ & $.86(.08)$ & $.91(.05)$ \\
\hline & & $N=170$ & $N=25$ & $N=21$ & $N=33$ \\
\hline \multirow{2}{*}{3} & & & $.81(.04)$ & $1.00(.00)$ & $.79(.07)$ \\
\hline & & & $N=79$ & $N=10$ & $N=33$ \\
\hline \multirow{2}{*}{4} & & & & $.81(.06)$ & $.75(.11)$ \\
\hline & & & & $N=42$ & $N=16$ \\
\hline \multirow{2}{*}{$\geq 5$} & & & & & $.89(.05)$ \\
\hline & & & & & $N=38$ \\
\hline
\end{tabular}

Table 1: Winning frequencies (standard deviations in parentheses) and number of observations $N$ by tenure and terms since last open seat election.

We argue that the data from the diagonal show that tenure effects are declining, provided that there are no dynamic considerations and the candidate densities are the same for the two types of elections. ${ }^{16}$ For a contradiction, assume that the tenure effects are zero, i.e., $\tau_{m}=0 \forall m$, and $F_{o}=F_{c}$. With no dynamic considerations, identical candidate densities and zero tenure effects, in each election voters choose the candidate with the highest permanent quality. Therefore, the distribution of quality of an incumbent who initially won an open seat election and who served $n$ terms is simply $\max \left\{F_{o, 1}, \ldots, F_{o, n+1}\right\}$. Thus, the expected quality is higher the more terms the incumbent has served, and the reelection probabilities should be increasing in the number of terms served, which we do not see in the data. If the tenure effects are increasing, rather than zero, this effect will be further exacerbated, showing that

16 There will be no dynamic considerations if either $\beta=0$ or $\delta_{m}$ is constant across $m$. While we cannot construct a proof of our argument if there are dynamic considerations or if the two candidate densities are different, it is still likely to be true. 
the tenure effects must be negative to explain this feature of the data. ${ }^{17}$

Next, we argue that tenure effects are negative. Since the effects are declining, it is sufficient to argue that $\tau_{1} \leq 0$. One might hypothesize that $\tau_{1}>0$ is necessary to explain why the reelection probabilities from the diagonal are all significantly higher than $50 \%$. However, there are two facets of the data that make this hypothesis unlikely.

First, in the absence of tenure effects, different densities, or dynamic considerations, selection alone implies that the incumbent will have a $67 \%$ chance of winning reelection, ${ }^{18}$ a number reasonably close to the actual probability, and one that will be higher if candidates in an open seat election are of higher quality. Of course, this explanation is not nonparametric in that it might be driven by the density of candidate quality, which is assumed to be normal. Nonetheless, the point is that selection by itself will imply high reelection probabilities for incumbents.

Second, we obtain further evidence against positive tenure effects by examining the change in reelection probabilities along the first row of Table 1. If, in fact, $\tau_{1}$ is positive, then we would expect that a senator who defeated an incumbent senator with one term of experience would, on average, have very high quality, as the electorate would have to endure a new senator instead of a senator with $\tau_{1}$ for one period. When this incumbent-defeating senator gets to his first reelection campaign, he should then have a very high chance of reelection: not only is his expected quality very high by selection, but now the tenure effects work to his favor. This logic can be generalized to argue that reelection probabilities should be rapidly increasing along any given row of Table 1 if the tenure effects are positive. Yet, there is no pattern of rapid increase in the probability of reelection along any row. Indeed, for the above case (which has the most observations), the incumbent-defeating senators win reelection only $72 \%$ of the time, as compared to the $79 \%$ reelection probability for one-term incumbents who won an open seat election. The implication is that

17 Note that a conventional "sophomore surge" analysis could not generate this result, as it either would not use any data beyond the $(1,1)$ cell or would lump all of these elements together.

18 We derive this figure by simulating the probability that the maximum of two draws from a normal density (the incumbent quality) is greater than a third draw (the challenger quality), since the decision rule in this case is simply to keep the higher quality candidate. 
the selection was not all that favorable, and hence that $\tau_{1}$ was not actually positive.

Finally, the decrease in reelection probabilities noted above also suggests that the open seat density is different from the incumbent-challenger density. The reason for this is that no matter what the tenure effects are, we would not expect to see decreasing reelection probabilities in any row, if the two densities are the same. The reason for this is that any difference in reelection probabilities between the candidates in a given row is due to selection, not tenure effects, since their tenures are the same. Moreover, the further down the row a candidate is, the more times he has been selected. This makes it very difficult to have selection generate the decreasing reelection rate when all candidates are drawn from the same density, regardless of the tenure effects. ${ }^{19}$

In contrast, different densities for candidates in open seat elections and challengers of incumbents can easily explain this decrease. In particular, if $\mu_{o}>0$ then a challenger facing an incumbent starts from a lower quality density than the incumbent, and hence may, on average, have lower quality upon winning than the incumbent had upon winning his first election. We verified this hypothesis by simulating voter decisions with no tenure effects or dynamic considerations but with positive $\mu_{o}{ }^{20}$ Choosing $\mu_{o}=1.0$ as an example, the winner of an open seat election would have a mean quality of 1.57 while a senator who defeated a one-term incumbent who won an open seat election would have a mean quality of only 1.34 , indicating a lower reelection probability in the second case. Thus, a positive $\mu_{o}$ can explain the decrease in reelection probabilities between the first two elements of the first row of Table 1.

In summary, the statistics of the data reported in Table 1 suggest that tenure effects $\tau_{m}$ are negative for $m \geq 1$, and that the density of candidates is higher for open seat elections than for incumbent-challenger elections. It is important to note that the above discussion considered the effects of selection, tenure, and candidate

19 While we cannot offer a formal nonparametric proof of this result, we were unable to find parameters for our model that resulted in decreasing probabilities of reelection along a row, when the two densities were the same.

20 Note that the decision rule in this case is still to keep the higher quality candidate. 


\begin{tabular}{c|c|c} 
& N. obs. & Estimate \\
\hline \hline$\delta_{1}$ & 593 & $0.1484(0.015)$ \\
$\delta_{2}$ & 358 & $0.2347(0.022)$ \\
$\delta_{3}$ & 199 & $0.2915(0.032)$ \\
$\delta_{4}$ & 100 & $0.3300(0.047)$ \\
$\delta_{5}$ & 90 & $0.3500(0.050)$
\end{tabular}

Table 2: Conditional exit probabilities by tenure (standard errors in parentheses)

density in isolation. We cannot consider all of these effects together using simple statistics. Moreover, with $\beta>0$, decisions will vary in complicated ways based on the retirement probabilities. In order to precisely quantify the sources of the incumbency advantage, we turn to our structural model.

\subsection{Base Structural Estimation Results}

Table 2 shows the conditional exit probabilities used in the estimation of the other parameters. The reported values are the mean probabilities from the data, with the standard errors then computed by using the number of observations. Not surprisingly, these are precisely estimated and increasing in tenure.

Table 3 shows the main structural estimation results, with bootstrapped standard errors in parentheses. Model 1 refers to the case where all candidates are drawn from the same distribution; in Model 2, we allow for the possibility that open seat candidates draw from a distribution with a mean different from candidates challenging incumbents. Our principal results are those from Model 2. The units can be understood by noting that the standard deviation on the distribution of quality is one.

In Model 2, we find a negative and statistically significant tenure effect. The effect is small: for the most common cases - incumbents of one, two, or three years of tenure - the tenure effects are estimated to be less than two-thirds of one standard deviation of the quality of challengers. We also find that candidates running in 


\begin{tabular}{c|c|c} 
& $\begin{array}{c}\text { Model 1 } \\
\left(f_{o}=f_{c}\right)\end{array}$ & $\begin{array}{c}\text { Model 2 } \\
\left(f_{o} \neq f_{c}\right)\end{array}$ \\
\hline \hline $\ln L$ & -504.851 & -486.751 \\
\hline$\tau_{1}$ & $-0.013(0.281)$ & $-0.646(0.200)$ \\
$\tau_{2}$ & $0.116(0.195)$ & $-0.657(0.211)$ \\
$\tau_{3}$ & $0.181(0.251)$ & $-0.615(0.259)$ \\
$\tau_{4}$ & $-0.754(0.581)$ & $-1.495(0.543)$ \\
$\tau_{5}$ & $0.241(0.516)$ & $0.738(0.523)$ \\
$\mu_{o}-\mu_{c}$ & 0 & $0.742(0.093)$
\end{tabular}

Table 3: Estimated parameters (standard errors in parentheses)

an open seat election are superior to challengers who run against incumbents; as a way to evaluate the magnitude, consider that the average candidate in an open seat election would be in the 75th percentile of the quality distribution for challengers to an incumbent. Moreover, the difference $\mu_{o}-\mu_{c}$ is precisely estimated. Thus, the results show that any advantage to incumbency is not inherent to the office, but rather the result of weaker candidates running as challengers against incumbents. The significance of $\mu_{o}-\mu_{c}$ implies that Model 1, which assumes that there is no difference in challenger quality across the two elections, cannot fit the data as well as Model 2. This is substantiated by the likelihood ratio test based on the log likelihoods reported in Table 3 , which vastly rejects Model $1\left(\chi^{2}(1)=36.2, p=.00\right)$. We prefer Model 2 for these reasons. Nonetheless, it is worth noting that Model 1 gives similar predictions in the sense that the tenure effects are estimated to be very small or negative.

As the estimates reveal that the direct effect of tenure is negative, the incumbency advantage is due to a combination of selection and incumbents facing weaker challengers. We now ask how big is the incumbent's benefit from facing weaker challengers, by simulating the equilibrium predictions of the model with different parameter values. In the data, incumbents win $78 \%$ of the time, a figure that is sim- 


\begin{tabular}{l|c|c|c} 
Tenure & Data & $\begin{array}{c}\text { Model } 1 \\
\left(f_{o}=f_{c}\right)\end{array}$ & $\begin{array}{c}\text { Model } 2 \\
\left(f_{o} \neq f_{c}\right)\end{array}$ \\
\hline \hline $1(N=474)$ & $.755(.020)$ & -0.029 & -0.003 \\
$2(N=249)$ & $.799(.025)$ & +0.001 & +0.006 \\
$3(N=122)$ & $.820(.035)$ & -0.010 & +0.002 \\
$4(N=58)$ & $.793(.053)$ & -0.042 & -0.036 \\
$\geq 5(N=38)$ & $.895(.050)$ & +0.021 & +0.009 \\
& & & \\
All $(N=941)$ & $.783(0.013)$ & -0.008 & +0.007
\end{tabular}

Table 4: Goodness of fit: reelection frequencies by tenure; data (standard deviations in parentheses), and difference between models' predictions and data

ilar to the estimated value of $79 \%$ for Model 2 . However, if incumbents were faced with challengers with the same distribution of quality as in an open seat election, then the model predicts that they would win only $63 \%$ of the time. If there were no quality differences across candidates whatsoever, then an incumbent would always have a $50 \%$ probability of reelection. In this sense, roughly half of the incumbency advantage is due to lower quality challengers.

A useful measure of goodness of fit is the ability of the models to reproduce reelection probabilities. Table 4 provides the reelection probabilities as a function of tenure.

Model 2 is able to fit the reelection percentages by tenure very accurately, particularly for the first three rows, which contain the bulk of the data. It would be troubling to argue that tenure effects are small if the model underpredicts reelection probabilities and hence does not generate sufficient incumbency advantage in winning probabilities. Model 2, however, accurately predicts winning probabilities with negative tenure effects. Thus, the model is not throwing out tenure effects at the expense of generating a high winning percentage for incumbents; it generates them all through the selection effect and the different densities for incumbents and 
Terms since last open seat election

\begin{tabular}{|c|c|c|c|c|c|c|c|c|}
\hline & 1 & 2 & \multicolumn{2}{|c|}{3} & \multicolumn{2}{|c|}{4} & \multicolumn{2}{|c|}{$\geq 5$} \\
\hline 1 & $\begin{array}{cc}.66 & .77 \\
(-.13) & (-.03)\end{array}$ & $\begin{array}{cc}.76 & .71 \\
(+.04) & (-.01)\end{array}$ & $\begin{array}{c}.81 \\
(+.18)\end{array}$ & $\begin{array}{c}.73 \\
(+.09)\end{array}$ & $\begin{array}{c}.84 \\
(+.26)\end{array}$ & $\begin{array}{c}.74 \\
(+.17)\end{array}$ & $\begin{array}{c}.86 \\
(+.09)\end{array}$ & $\begin{array}{c}.75 \\
(-.02)\end{array}$ \\
\hline 2 & & $\begin{array}{cc}.75 & .82 \\
(-.03) & (+.05) \\
\end{array}$ & $\begin{array}{c}.81 \\
(+.05) \\
\end{array}$ & $\begin{array}{c}.77 \\
(+.01) \\
\end{array}$ & $\begin{array}{c}.86 \\
(+.01) \\
\end{array}$ & $\begin{array}{c}.80 \\
(-.06) \\
\end{array}$ & $\begin{array}{r}.87 \\
(-.04) \\
\end{array}$ & $\begin{array}{c}.78 \\
(-.13) \\
\end{array}$ \\
\hline 3 & & & $\begin{array}{c}.78 \\
(-.03)\end{array}$ & $\begin{array}{c}.84 \\
(+.03)\end{array}$ & $\begin{array}{c}.81 \\
(-.19)\end{array}$ & $\begin{array}{c}.78 \\
(-.22)\end{array}$ & $\begin{array}{c}.86 \\
(+.07)\end{array}$ & $\begin{array}{c}.80 \\
(+.01)\end{array}$ \\
\hline 4 & & Model 1 Model 2 & & & $\begin{array}{c}.71 \\
(-.10)\end{array}$ & $\begin{array}{c}.78 \\
(-.03)\end{array}$ & $\begin{array}{c}.79 \\
(+.04)\end{array}$ & $\begin{array}{c}.73 \\
(-.02)\end{array}$ \\
\hline$\geq$ & & & & & & & $\begin{array}{c}.92 \\
(+.02)\end{array}$ & $\begin{array}{c}.90 \\
(+.01)\end{array}$ \\
\hline
\end{tabular}

Table 5: Goodness of fit: Models 1 and 2 predicted reelection frequencies by tenure and terms since open seat (difference between predictions of models and data in parentheses)

challengers. Model 1 does less well at fitting these moments, demonstrating the importance of allowing for different densities.

Note also that the inference that tenure effects are negative or small is robust to the assumption of exogenous retirement. If senators were retiring because they were expecting a loss, then the senators who choose to run for reelection would have better selection than the unconditional average. This positive selection would then be reflected in the tenure effects, implying that our tenure effects would be upwardly biased.

We further evaluate the goodness of fit of the estimated models by examining how well they match the conditional probabilities of reelection by terms served and terms since an open seat election given in Table 1. As noted in Section 5.1, these moments summarize much of the important identification of the model. Table 5 provides these probabilities for our two models, as well as indicating the difference between the data and the predictions of the models.

Model 2 is generally successful at matching these moments of the data. In all but six cells, the predictions from Model 2 are within one standard deviation of 
the reelection probabilities from the data. In all but one cell, the predictions from Model 2 are within two standard deviations of the percentages from the data.

In contrast, Model 1 does much less well at matching these moments. In particular, Model 1 underpredicts by 13 percentage points the reelection probability for the case with the most observations, of an incumbent who won an open seat election seeking his first reelection (row 1, column 1), but overpredicts by 4 percentage points the reelection probability of a one-term incumbent who obtained office by defeating an open seat winner who had served one term (row 1, column 2). The reason for this relates to the discussion in Section 5.1: the incumbents in these two cells have identical tenure effects, but the column 2 cell has a better selection. Thus, with the same candidate density for challengers in the open-seat and incumbent-challenger elections, Model 1 has a very hard time explaining the drop in the probability of reelection between these two cells.

In comparison to our models, conventional "sophomore surge" analysis either looks only at the case where the number of terms since the last open seat election is one, or lumps together all one-term incumbents. By examining the reelection probability for candidates as a function of the entire history since an open seat election, our models generate results that are robust to different tenure effects and are substantiated in the data. Consistent with our results, the Levitt and Wolfram (1997) study of House incumbency advantage finds that a large fraction of the incumbency advantage is the result of the ability of incumbents to deter high quality challengers from running against them. However, they also find evidence of substantial tenure effects, which we do not find. Whether this discrepancy is the result of different modeling assumptions, or evidence of different causes of incumbency advantage between the House and the Senate is an interesting topic for further research.

\subsection{Robustness to additional sources of heterogeneity}

In the analysis so far, candidates may be different because of different idiosyncratic draws from the quality distribution. The only source of heterogeneity in the candidate quality distribution arises from whether they run against an incumbent or in 
an open seat election. We have been parsimonious in specifying sources of heterogeneity because we wanted to focus on the effects of selection on the incumbency advantage and because predicted moments from the structural estimation, based on reelection probabilities by candidate tenure and history, fit the data reasonably well.

As a robustness check, this section investigates whether the inclusion of additional candidate characteristics could potentially lead to different results.

\section{Previous experience in the U.S. House of Representatives}

Several candidates become senators as part of a career path that starts in state legislatures, and continues in the U.S. House of Representatives. We investigated whether previous experience in the House significantly affects the probability of a senator winning reelection. We found that among senators that just won an open seat, those with House experience win reelection $81 \%$ of the time, whereas those without House experience win reelection $78 \%$ of the time. ${ }^{21}$ The similarity between these reelection probabilities suggests that including experience as an additional source of heterogeneity to the estimation would probably not add much explanatory power.

\section{Party membership}

In the political science literature, party membership is suggested to be a possible source of incumbency advantage. Presidential coat-tail effects, for example, could affect senators' winning probabilities. On a conceptual level, the main difficulty with including party as an exogenous characteristic affecting quality is that voter opinion swings over time, and the effect of party membership may therefore vary over time. One possibility is that in some states at some points in time, voters have special preferences for candidates from one party. In the context of a dynamic model, one could model these preferences by allowing for the party of the senator who exited at the end of the previous chain to affect the utility flow from a candidate of that party in the current chain. We could then estimate the amount of extra utility from having a candidate of the same party, and would generally expect it to be positive.

21 This is consistent with results from Diermeier et al. (2002). 


\begin{tabular}{c|c|c}
$\ln L=-483.698$ & Type 1 & Type 2 \\
\hline \hline$\tau_{1}$ & $8.00(11.95)$ & $-0.86(0.21)$ \\
$\tau_{2}$ & $3.44(12.10)$ & $-0.68(0.34)$ \\
$\tau_{3}$ & $8.00(21.92)$ & $-0.83(0.39)$ \\
$\tau_{4}$ & $8.00(15.12)$ & $-1.84(0.51)$ \\
$\tau_{5}$ & $3.62(8.16)$ & $-0.83(0.50)$ \\
$\mu_{o}-\mu_{c}$ & $-3.55(6.73)$ & $0.901(0.23)$ \\
Type prob. & $0.091(0.10)$ &
\end{tabular}

Table 6: Estimates for model with unobserved heterogeneity

Yet, in our data, candidates from the same party of the previous incumbent win only $39 \%$ of the open seat elections. With a positive local preference for one party, we would expect this figure to be greater than $50 \%$. Thus, this suggests that there is no special preference for a party within states.

\section{Unobserved heterogeneity}

Despite the basic evidence we presented above, experience, party membership, and other factors may affect winning probabilities. The main problem is that our basic specifications do not account for the possibility that some states have huge, positive tenure effects ("safe" states where, for instance, a candidate of the prevailing political party has an inherent advantage), while others have moderately negative tenure effects.

In order to understand whether other sources of heterogeneity may affect our results, we tested the presence of unobserved heterogeneity by assuming that there are two types of chains, characterized by different values of the tenure effects $\tau_{1}-\tau_{5}$, and the open seat candidates' advantage $\mu_{o}-\mu_{c}$. We estimated the two sets of parameters (one per type), together with the type probability. ${ }^{22}$ The results are

22 The dynamic optimization problem is solved for each type, providing a likelihood function conditional on type. The total likelihood is a mixture over types weighted by sample probabilities, which are estimated together with the type-specific parameters (see, e.g., Eckstein and Wolpin (1990), or Keane and Wolpin (1997)). 


\begin{tabular}{c|c|c}
$\ln L=-479.023$ & Type 1 & Type 2 \\
\hline \hline$\tau_{1}$ & $5.86(5.02)$ & $-0.90(0.21)$ \\
$\tau_{2}$ & $1.09(27.02)$ & $-0.67(0.29)$ \\
$\tau_{3}$ & $7.99(51.69)$ & $-0.89(0.37)$ \\
$\tau_{4}$ & $4.54(3.82)$ & $-1.88(0.45)$ \\
$\tau_{5}$ & $1.76(4.95)$ & $-0.86(0.42)$ \\
$\mu_{o}-\mu_{c}$ & $-3.40(3.19)$ & $0.95(0.20)$ \\
\multicolumn{2}{c}{ Type Probabilities } \\
After 1945, South & $0.024(0.08)$ & $0(0.06)$ \\
After 1945, not South & $0.166(0.15)$ & $0.281(0.14)$ \\
Before 1945, South &
\end{tabular}

Table 7: Estimates, unobserved heterogeneity with type probability function of observables

reported in Table 6, with derivative-based standard errors reported in parentheses. ${ }^{23}$

We estimate two distinct type of chains. With probability $9.1 \%$, a chain will be of Type 1 and have large and positive tenure effects, while with the complementary probability it will have negative and significant tenure effect. These results suggest that incumbency advantage is big in some chains (candidates almost never lose in chains of Type 1). The fit of the data, however, does not significantly improve from the Model 2 specification. ${ }^{24}$ Moreover, a likelihood ratio test cannot reject the one-type specification. ${ }^{25}$

We also investigated similar specifications, but with the type probabilities as a function of the region and date the chains began. We computed several such specifications, but report only one of them in Table 7 in the interest of parsimony.

\footnotetext{
23 We chose not to bootstrap the standard errors in these cases because of computational constraints.

24 Details are available from the authors upon request.

25 Note that we are testing a boundary condition using a two-sided test. The results from the test are therefore only indicative.
} 
None of these specifications substantially improve the fit of the data. According to likelihood ratio tests, none of them significantly improves on the basic specification without unobserved heterogeneity.

\section{Discussion and Conclusion}

We analyze the causes of incumbency advantage for the U.S. Senate by structurally estimating a dynamic optimizing model of voter behavior. Our results are identified by examining the impact of the entire history of election outcomes following an open election on the probability that an incumbent will win, conditioning on the tenure of the incumbent. We find that the incumbency advantage is due to two effects. Incumbent senators are, on average, selected to be of high quality due to their past successes in winning elections. In addition, incumbent senators are able to deter high quality challengers. We find no evidence of other benefits intrinsic to incumbency: tenure appears to provide a small disadvantage in reelection.

Our result that tenure is not an important determinant of the incumbency advantage stands in contrast to some of the literature. However, studies of incumbency advantage have mostly focused on the U.S. House of Representatives. Relative to the House, tenure in the Senate may be less important, because committee assignments are not as important.

Our result that incumbents face weaker challengers does have precedent in the literature. For instance, Levitt and Wolfram (1997) find the same effect in House elections, although with a different identification mechanism. Note that the selection effect still implies that incumbent senators are hard to defeat, and therefore our finding that potential challengers might be dissuaded from running against incumbents is not puzzling.

There is substantial information available about elections besides the history of a seat that might be relevant that are not in our base model. The results presented in Section 5.3, in particular our estimates from the specifications with unobserved heterogeneity, suggest that our basic conclusions should not be affected by the inclusion of additional information about candidates. However, inclusion of additional 
variables can potentially disentangle the magnitudes of different sources of tenure effects. We believe this is an interesting direction for future research.

\section{A Appendix}

\section{A.1 Proof of Lemma 1}

Proof. Denote by $M$ the finite set of allowable tenures for an incumbent. We prove the lemma by first showing that $V(q, m)$ is increasing in the first argument, using standard recursive techniques (see Stokey et al. (1989)). Denote by $C$ the metric space of all continuous functions $g: Q \times M \rightarrow \mathbb{R}$ that are weakly increasing in the first argument, where the metric is defined by the sup norm. Note that $C$ is a complete metric space since these countinuous functions, on a compact domain, must be bounded. Define the mapping $T$ for any function $g \in C$ by

$$
\begin{aligned}
T(g) & =\left(1-\delta_{m}\right) \int \max \left\{\begin{array}{c}
\left(q+\tau_{m}+\beta g(q, m+1)\right), \\
\left(q_{c}+\tau_{0}+\beta g\left(q_{c}, 1\right)\right)
\end{array}\right\} d f\left(q_{c}\right) d q_{c} \\
& +\delta_{m} \iint \max \left\{\begin{array}{c}
\left(q+\tau_{0}+\beta g(q, 1)\right), \\
\left(q_{c}+\tau_{0}+\beta g\left(q_{c}, 1\right)\right)
\end{array}\right\} d f(q) d q d f\left(q_{c}\right) d q_{c}
\end{aligned}
$$

Notice that, whenever $g$ is weakly increasing and continuous, so is $T(g)$, so $T$ is an operator, $T: C \rightarrow C$. Notice that $T$ meets Blackwell's sufficient conditions for a contraction: for any function $g^{\prime} \geq g, T\left(g^{\prime}\right) \geq T(g)$, and for a constant $c$, $T(g+c)=T(g)+\beta c, 0<\beta<1$. Hence, by the contraction mapping lemma, for all functions $V_{0} \in C$, the sequence defined by $V_{n}=G\left(V_{n-1}\right)$ converges to a function $V \in C$ that is the unique fixed point of the operator $T$. Since $V$ is the fixed point, it is exactly the value function that solves the dynamic programming problem. Since $V \in C$, the value function $V$ is weakly increasing in the first argument.

Note that $q_{c}$ only shows up in two places in the choice of candidates (once in the current reward from choosing the challenger, once in the future value if the challenger is chosen), and if $V$ is weakly increasing in the first argument, the total discounted reward from choosing the challenger is strictly increasing in $q_{c}$, while 
the discounted reward from choosing the incumbent is constant in $q_{c}$. As a result, $r\left(q, q_{c}, m\right)$ must be decreasing in $q_{c}$ for any fixed $q$ and $m$.

\section{A.2 Details on the numerical computation}

The permanent quality distribution $F$ is continuous, which implies that we need to approximate the value function in our computation. We choose a discrete grid approximation, and use 401 evenly spaced grid points between -6 and +6 , in order to capture the tails of the standard normal density (351 grid points and $-8 /+8$, respectively, in the unobserved heterogeneity specifications). We use linear interpolation in order to create a smooth policy function $\bar{q}$, necessary for an efficient search for the maximum likelihood parameters.

We find the parameter vector that maximizes the likelihood by using numerical search algorithms. We use two different algorithms: a routine that we developed that combines the simplex method with random jumps and the method of simulated annealing by Goffe et al. (1992).

\section{References}

Ansolabehere, Stephen and James M. Snyder Jr., "The Incumbency Advantage in U.S. Elections: An Analysis of State and Federal Offices, 1942-2000," Election Law Journal, 2002, 1 (3), 315-38.

_ and _, "Using Term Limits to Estimate Incumbency Advantages When Officeholders Retire Strategically," Legislative Studies Quarterly, forthcoming 2004.

Cover, Albert D., "One Good Term Deserves Another: The Advantage of Incumbency in Congressional Elections," American Journal of Political Science, August 1977, 21 (3), 523-41.

- and David R. Mayhew, "Congressional Dynamics and the Decline of Competitive Congressional Elections," in Lawrence C. Dodd and Bruce I. Oppenheimer, eds., Congress Reconsidered, New York, NY: Praeger, 1977. 
Cox, Gary W. and Jonathan N. Katz, "Why did the Incumbency Advantage in the U.S. House Grow?," American Journal of Political Science, May 1996, 40 (2), 478-97.

Diermeier, Daniel, Michael Keane, and Antonio Merlo, "A Political Economy Model of Congressional Careers," PIER Working Paper 02-029 July 2002.

Eckstein, Zvi and Kenneth I. Wolpin, "Estimating a Market Equilibrium Search Model from Panel Data on Individuals," Econometrica, 1990, 58, 783808.

Erikson, Robert S., "The Advantage of Incumbency in Congressional Elections," Polity, 1971, 3, 395-405.

Fiorina, Morris P., Congress: Keystone of the Washington Establishment, second ed., New Haven: Yale University Press, 1989.

Gelman, Andrew and Gary King, "Estimating Incumbency Advantage without Bias," American Journal of Political Science, November 1990, 34 (4), 1142-64.

Goffe, William L., Gary D. Ferrier, and John Rogers, "Simulated Annealing: An Initial Application in Econometrics," Computer Science in Economics \& Management, 1992, 5 (2), 133-46.

Heckman, James J. and Burton Singer, "A Method for Minimizing the Impact of Distributional Assumptions in Econometric Models for Duration Data," Econometrica, March 1984, 52 (2), 271-320.

Keane, Michael P. and Kenneth I. Wolpin, "The Career Decisions of Young Men," Journal of Political Economy, June 1997, 105 (3), 473-522.

Kiewiet, Roderick D. and Langche Zeng, "An Analysis of Congressional Career Decisions, 1947-1986," The American Political Science Review, Dec 1993, 87 (4), 928-41. 
Lee, David S., "The Electoral Advantage to Incumbency and Voters' Valuation of Politicians' Experience: A Regression Discontinuity Analysis of Elections to the U.S.," NBER Working paper \#8441 August 2001.

Levitt, Steven D. and Catherine D. Wolfram, "Decomposing the Sources of Incumbency Advantage in the U.S. House,", Legislative Studies Quarterly, February 1997, 22 (1), 45-60.

Magnac, Thierry and David Thesmar, "Identifying Dynamic Discrete Decision Processes," Econometrica, March 2002, 70 (2), 801-16.

Mayhew, David R., Congress: The Electoral Connection, Yale University Press, 1974.

Mitchell, Matthew F., "The Scope and Organization of Production: Firm Dynamics Over the Learning Curve," Rand Journal of Economics, Spring 2000, 31 (1), 180-205.

Rust, John, "Optimal Replacement of GMC Bus Engines: An Empirical Model of Harold Zurcher," Econometrica, September 1987, 55 (5), 999-1033.

Samuelson, Larry, "A Test of the Revealed-preference Phenomenon in Congressional Elections," Public Choice, 1987, 54, 141-69.

Stokey, Nancy, Robert Lucas, and Edward Prescott, Recursive Methods in Economic Dynamics, Cambridge, Ma: Harvard University Press, 1989. 